\section{A prospective outcome study of membranous and solid distal common canalicular obstructions}

PN Shams ${ }^{1,2}$, A Pirbhai $^{3}$ and D Selva ${ }^{2}$

\begin{abstract}
Purpose To prospectively evaluate the surgical outcomes of membranous and solid

Eye (2016) 30, 621-626; doi:10.1038/eye.2016.11; published online 12 February 2016
\end{abstract} distal common canalicular obstructions (CCOs) following endoscopic dacryocystorhinostomy (EnDCR) and lacrimal intubation combined with either membranotomy or trephination. Methods This was a prospective, nonrandomized, consecutive interventional case series. Inclusion criteria included patients undergoing EnDCR with evidence of a membranous block or more solid obstruction of the distal common canaliculus, treated with membranotomy or canalicular trephination. Complete CCO was confirmed pre-operatively using dacryocystography and dacryoscintigraphy. All patients received bicanalicular intubation for 3 months with a minimum follow-up of 12 months. Functional and anatomical success was assessed at 4 weeks, 3 months, and 12 months following surgery. Functional success was defined as subjective improvement of epiphora and anatomical success as the presence of a patent ostium and a positive dye test on nasal endoscopy. Results Twenty-nine patients were included in the study with a mean age of 58 years. Twentyone patients $(72 \%)$ received a membranotomy and eight (28\%) required trephination. At 12 months, the functional and anatomical success rate in the membranotomy group was $90 \%$ $(19 / 21)$ and $100 \%(21 / 21)$, respectively, and in trephination group the functional and anatomical success rate was $63 \%(5 / 8)$. There were no intraoperative or lacrimal stent-related complications. Conclusions Identifying and excising distal CCOs in association with EnDCR and lacrimal intubation is associated with a high degree of functional ( $83 \%$ ) and anatomical $(\mathbf{9 0} \%)$ success. The success of membranous obstructions appear be superior to outcomes for solid obstructions of the distal common canaliculus that require trephination.

\section{Introduction}

The treatment of common canalicular obstruction (CCO) remains a challenge in lacrimal surgery. Distal CCO, at its junction with the lacrimal sac at the common internal ostium (CIO), may be solid or membranous in nature. ${ }^{1,2}$ The management of these entities includes canalicular trephination and membranectomy, membranotomy or membrane lysis. Published treatment outcomes are difficult to compare between studies because of the variable definition of CCO. Clinically, distal and more proximal CCOs, and membranous and more solid obstructions are often grouped together; however, there are considerable differences in treatment outcome of canalicular obstructions based on the exact location and extent of the in an office setting, while others are used as an adjunct to more invasive lacrimal surgery. ${ }^{2-8}$ In the setting of transnasal endoscopic dacryocystorhinostomy (EnDCR), one previous trephination for CCOs. ${ }^{9}$ To our knowledge, this is the first study that has employed membranectomy without trephination and has attempted to evaluate the outcome of both membranous and more solid distal obstructions of the common canaliculus. This is also the first study to our knowledge that has employed membranotomy alone without trephination with EnDCR for CCOs. Employing strict inclusion criteria, we sought to prospectively investigate the success rate in treating $\mathrm{CCO}$, using either trephination or membranotomy, and silicone lacrimal intubation at the time of EnDCR (Figure 1). obstruction. Some techniques can be performed study has reported retrospective outcomes of
${ }^{1}$ Adnexal Service, Moorfields Eye Hospital, London, UK

${ }^{2}$ Department of Ophthalmology and Visual Sciences, South Australian Institute of Ophthalmology, University of Adelaide, Adelaide, South Australia, Australia

${ }^{3}$ Oculoplastic Service, Niagara Health System, Fort Erie, Ontario, Canada

Correspondence: PN Shams, Moorfields Eye Hospital at St George's Hospital, Blackshaw Road, London SW17 OQT, UK Tel: +44 (0) 208725 2062; Fax: +44 (0) 2087250372 E-mail: pari.shams@gmail.com

Received: 10 June 2015 Accepted in revised form: 4 November 2015 Published online: 12 February 2016 


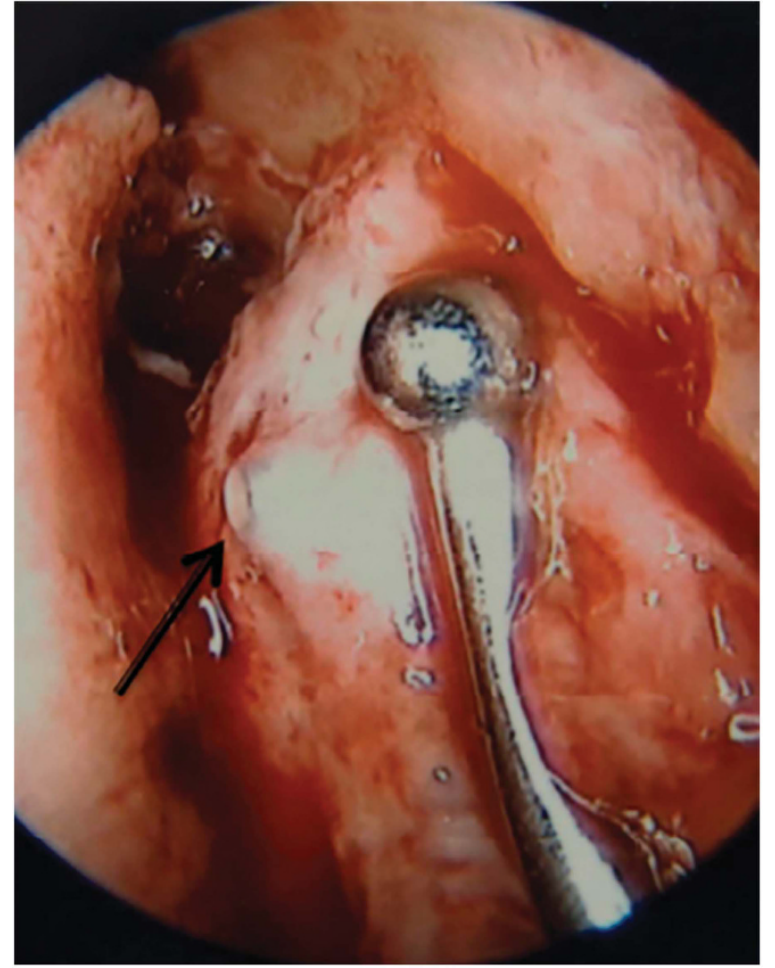

Figure 1 Intraoperative transnasal endoscopic view of an open left lacrimal sac. A ball probe is seen reflecting anterior lacrimal sac flap with the black arrow demonstrating the end point of trephining a solid distal common canalicular obstruction, as the trephine is emerging, at the site of the common internal ostium, with only a very thin layer of tissue remaining over it before it enters the nasal space.

\section{Materials and methods}

This was a prospective, non-randomized, noncomparative, single-surgeon, single-center interventional case series. Consecutive patients undergoing EnDCR for nasolacrimal system obstruction between January 2007 and December 2009 were included. Patients undergoing revision endoscopic DCR were excluded. This was part of the larger prospective study to investigate a variety of factors influencing functional and anatomical outcomes following EnDCR surgery, which have been published. ${ }^{10-15}$ As part of this study, patients with distal CCOs were analyzed separately. Demographics were recorded and symptoms were evaluated pre-operatively using a tearing symptoms score questionnaire graded using the Munk score. ${ }^{16}$ (Munk score: $0=$ no epiphora;

$1=$ occasional epiphora requiring wiping less than twice a day $(<2) ; 2=$ wiping $2-4$ times per day; $3=$ wiping 5-10 times per day; and $4=$ wiping $>10$ times per day or continuous tearing). All patients underwent lacrimal irrigation with patency and reflux documented. Location of a soft-stop in millimeters from the punctum was recorded. Only those with a soft-stop of $7 \mathrm{~mm}$ or more from the punctum were included in the study. All patients underwent lacrimal imaging with a dacryocystogram (DCG) and dacryoscintogram (DSG). Patients with presumed canalicular stenosis but patent lacrimal system on DCG were excluded, as were those with a history of lacrimal surgery. The EnDCR was performed under general anesthesia (GA) or local anesthesia with sedation (LAS). Membranous obstructions were defined as transparent, where the metal lacrimal probe could be easily visualized behind the membrane. Solid obstructions were so defined where the metal probe could not be visualized. This study followed the tenets of the Declaration of Helsinki and was approved by the local institutional research and ethics board.

\section{The surgical technique}

A standardised technique of EnDCR, as described previously, was used in all cases. ${ }^{17}$ A topical decongestant is applied to the nasal cavity, and the lateral nasal wall infiltrated with 2\% lidocaine with 1:80 000 epinephrine. A $30^{\circ} 4-\mathrm{mm}$ endoscope is used throughout. A nasal mucosal flap is fashioned starting $8 \mathrm{~mm}$ above the insertion of the middle turbinate on the lateral nasal wall. A suction Freer elevator is used to lift the nasal mucosal flap which is tucked between the middle turbinate and the nasal septum and trimmed later in the procedure. The hard bone of the frontal process of the maxilla is removed with a forward-biting sphenoid punch. An angled $\left(15^{\circ}\right)$ coarse diamond burr attached to a microdebrider (Medtronic Xomed, Jacksonville, FL, USA) is used to remove the remaining thick bone over the fundus of the lacrimal sac. In cases of CCO, the Bowman probe cannot not be advanced into the lacrimal sac, as is typically done to aid sac opening. The sac wall is therefore opened as far posteriorly as possible with a right-angled DCR spear knife (Medtronic Xomed), taking care not to advance the knife too far and avoiding damage to anterior sac wall and CIO. A DCR sickle knife (Medtronic Xomed) is used to make the releasing cut in the anterior flap, and the microscissors in the posterior flap allowing them to lie flush with the lateral nasal wall. The nasal mucosal flap is trimmed appropriately, so that it does not overlie or obstruct the new ostium. The CIO is then carefully inspected to evaluate the nature of the obstruction. Where a membrane is seen overlying the metal tip of the lacrimal probe at the $\mathrm{CIO}$, a membranotomy is performed by making an incision in the membrane over the metal probe using a keratome and if necessary extending it with microscissors. A solid obstruction close to the $\mathrm{CIO}$ is identified by appreciating that the lacrimal probe is abutting the medial wall of the marsupalised lacrimal sac without being able to visualize its metal tip at the CIO. Here trephination is performed using a canalicular (Bvi Visitec, Sarasota, FL, USA) 
lacrimal minitrephine (Sisler), ${ }^{18}$ Beaver-Visitec International Ltd). The minitrephine is $38 \mathrm{~mm}$ long and $0.80 \mathrm{~mm}$ in diameter $(21 \mathrm{G})$. It has a plastic hub affixed to the shaft proximally by which it can be grasped and rotated. The instrumental stylet is removable. The trephine is lubricated and inserted through the punctum and along the canaliculus to site of obstruction. It is angled toward the $\mathrm{CIO}$, then rotated in a boring fashion until the tip is seen to emerge into the lacrimal sac, and a cylinder of scar tissue passes into the lumen of the trephine. The assembly is then withdrawn and a bicanalicular silicone stent $(4.5 \mathrm{~cm} \times 0.90 \mathrm{~mm})$ (Visitec) is placed. A $10 \times 4 \mathrm{~mm}$ long Silastic sleeve is glided over the tubes. A check is made to ensure that there is no tension on the stent. Two Ligaclips (Ethicon Inc., Somerville, NJ, USA) are placed below the Silastic sleeve and the stent is trimmed. Gelfoam (Pharmacia, Sydney, NSW, Australia) is placed over the flaps. No nasal packs were used. Post-operative instructions include ice packs for $48 \mathrm{~h}$, daily saline nasal douching and avoidance of nose blowing for 2 weeks.

At 4 weeks, all patients were examined to assess ostium patency. Ostial closure or other complications with subsequent interventions were recorded. All patients remained intubated with the lacrimal stent for 12 weeks. At 12 months, the Munk score and a full clinical assessment was obtained, which included lacrimal irrigation, endoscopic evaluation of the ostium, and fluorescein dye test, the latter reported as positive or negative. Outcomes were measured in terms of functional and anatomical success.

Functional success was defined as a subjective improvement in epiphora at 12 months, with a Munk score of 0 or 1 . Anatomical success was defined as the presence of a patent ostium on nasal endoscopy and a positive endoscopic dye test.

\section{Results}

One hundred and sixty two cases undergoing EnDCR were recruited to the study, among which 29 were simultaneously treated for CCO obstruction. The mean age of patients with CCO was 58 years (range 19-87), 72\% $(n=21)$ were female. Ten percent $(n=3)$ had a past history either of severe conjunctivitis, canalicular laceration, or docetaxel use. The mean pre-operative Munk score in patients with CCO was 3.76. Lacrimal probing revealed a soft-stop at a mean distance of $9 \mathrm{~mm}$ (range 7-11 $\mathrm{mm}$ ) from the punctum, and reflux from the opposite canaliculus on irrigation. All patients had DCG findings consistent with $\mathrm{CCO}$ and showed pre-sac delay on DSG. The mean intra-operative distance of membranous obstruction to punctum was $9 \mathrm{~mm}$, whereas in the trephination group, the obstruction was at $8 \mathrm{~mm}$. Four cases $(13 \%)$ underwent surgery under LAS and the remainder had GA. Intra-operatively, a solid distal CCO was found in eight cases (28\%), which were treated by trephination. In 21 cases (72\%), a membrane was visualized at the $\mathrm{CIO}$ when a membranotomy was performed. There were no cases where membranotomy failed and a trephination was required. All patients were intubated with a bicanalicular silicone lacrimal stent for 12 weeks. There were no intra-operative complications. The mean Munk score 12 months following surgery in both groups was 0.72 . There was a significant improvement in the mean Munk score in the membranotomy group of -3 and the trephination group of -2.75 .

The overall anatomical success rate for both membranous and solid CCO was 90\% (26/29) and the functional success rate was $83 \%(24 / 29)$ (Table 1). The anatomical success rate in the membranotomy group at 12 months post EnDCR was 100\% (21/21). One patient in this group required a repeat EnDCR at 5 months due to closure of the DCR ostium; but notably at the time of redo-surgery, the opening of the $\mathrm{CIO}$ was patent and there was complete anatomic and functional success at 12 months. The functional success rate at 12 months in the membranotomy group was 90\% (19/21). Two cases demonstrated residual, although improved, pre-sac delay on post-operative DSG. One patient underwent a lower lid-tightening procedure, improving the Munk score from 3 to 1 . The other declined further intervention. The anatomical and functional success rate in the trephination group at 12 months post EnDCR was $63 \%(5 / 8)$. The three failures in the trephination group showed solid blockage at the distal common canaliculus, confirmed on lacrimal irrigation. One patient had repeat

Table 1 Anatomical and functional success rates of membranous vs solid common canalicular obstruction

\begin{tabular}{|c|c|c|c|}
\hline & \multicolumn{2}{|c|}{ Technique and type of distal common canalicular obstruction } & \multirow[t]{2}{*}{ Total } \\
\hline & Membranotomy for Membranous/thin CCOs & Trephination for Solid/thick CCOs & \\
\hline Number of cases & 21 & 8 & 29 \\
\hline \multicolumn{4}{|l|}{$\begin{array}{l}\text { Success rate } 12 \text { months } \\
\text { following EnDCR }\end{array}$} \\
\hline Anatomical success & $21 / 21(100 \%)$ & $5 / 8(63 \%)$ & $26 / 29(90 \%)$ \\
\hline Functional success & $19 / 21(90 \%)$ & $5 / 8(63 \%)$ & $24 / 29(83 \%)$ \\
\hline
\end{tabular}

Abbreviations: CCO, common canalicular obstruction; EnDCR, endoscopic dacryocystorhinostomy. 
trephination and intubation at 12 months and remains asymptomatic at 6 months follow-up with the lacrimal stent kept in situ as per patient's request. Another patient underwent repeat trephination and intubation 9 months after surgery. The stent was left in situ for 6 months; however, there was recurrent $\mathrm{CCO}$ within a few weeks of stent removal. Subsequent Lester Jones tube insertion led to success, maintained at 28 months follow-up. The third patient who had failed trephination declined further intervention; this was the patient with a history of severe conjunctivitis. The patients with a past history of canalicular laceration $(n=1)$ and docetaxel therapy were also fond to have more solid distal CCOs and were successfully treated following the initial procedure of EnDCR, trephination, and lacrimal stenting. The anatomical and functional success rate of membranotomy for thinner canalicular obstructions was higher than canalicular trephination of thicker, more solid obstructions.

\section{Discussion}

To our knowledge, this is the first study to (1) prospectively assess the outcome of CCO in patients undergoing EnDCR, (2) perform membranotomy in the setting of EnDCR, and (3) to differentiate the outcome of surgery based on the location and type of CCO. Although the distinction between membranous and solid CCOs was subjective, by the ability to visualize the metallic probe at the time of surgery, it was made by a same surgeon in all cases. The majority of CCOs (72\%) had a visible membranous obstruction at the CIO. The anatomical success of treating thinner CCO appear be superior to thicker, more solid distal CCOs. Interpreting the current literature on CCO is problematic since previous studies commonly group all distal CCOs together, without clearly distinguishing between membranous and solid types. Furthermore, in the setting of primary DCR, distal canalicular obstruction remains among the most common etiology cited for failure, $1,7,19-21$ which in some cases, is because of the fact that the pre-operative evaluation fails to detect a canalicular obstruction before DCR surgery. ${ }^{2,22}$ Although careful lacrimal probing and irrigation should reveal the 'soft-stop' in the setting of distal canalicular obstructions, the differentiation from a 'hard-stop' may on occasion be difficult. Obstructions at the $\mathrm{CIO}$ are thought to arise from a condensation or adherence of the valve of Rosenmüller to the medial wall of the lacrimal sac mucosa. An early description of this feature was reported by Welham among cases of failed primary external DCR. ${ }^{7}$ They advocated incising the visible membranous scar over the CIO. ${ }^{7}$ Boboridis performed membranectomies at the $\mathrm{CIO}$ during external DCRs and described these as varying between 'a thin diaphanous membrane to a dense fibrous condensation'. ${ }^{2}$ The authors anecdotally note that canalicular probing with a metal guide such as a Bowman probe can lead to a false impression of canalicular obstruction despite pre-operative DCGs confirming canalicular patency. The tip of the probe may get caught within the mucosal folds of the CIO or lacrimal sac mucosa, falsely suggesting an obstruction, an issue noted by others. ${ }^{23,24}$ However, gentle redirection of the probe under direct visualization of the $\mathrm{CIO}$ and adequate lateral traction of the eyelid will generally obviate this problem. Although DCG and DSG are not routinely used in the setting of $\mathrm{CCO}$, we employed these tests in addition to clinical diagnostic techniques to ensure the inclusion of only true $\mathrm{CCO}$ in this prospective study. Welham reported an 85-89\% success rate among 208 external DCR reoperations of which 108 were found to be due to CCO. ${ }^{7}$ Boboridis reported success rates of $93 \%$ (64 out of 69) when a membrane was identified during primary external DCR and silicone intubation. DCG and DSG were performed in some patients, the former failing to correctly identify the CCO in $43 \%(30 / 69) .^{2}$ Details of DCG findings were not reported, raising questions about the nature of the CCO encountered in their retrospective study. External DCR with membranectomy and double silicone intubation has been reported, with anatomic and functional success rates of $91-95 \%$ and $83-87 \%$, respectively, compared with single-stent intubation of 75 and $70 \%$, respectively. 4,25

Canalicular trephination with subsequent intubation is widely used for obstructions of the distal and common canaliculus as an office based intervention, with Sisler reporting success rates of $83 \%$ in 18 cases. ${ }^{6}$ The success of the technique is largely based on the site of the obstruction, with Khoubian reporting 66\% complete relief in cases of distal lower canalicular obstructions (5-10 $\mathrm{mm}$ from the punctum), to 59\% complete relief in cases of CCO (>10 $\mathrm{mm}$ from the punctum) when treated with trephination and intubation. ${ }^{5}$ Yang employed trephination followed by balloon canaliculoplasty in patients with distal monocanalicular and CCO with success rates of $54 \% .{ }^{8}$ Trephination and intubation during EnDCR surgery has not been widely reported. In a small series of five patients, Nemet reported symptomfree results in four out of five patients following EnDCR with trephination and application of mitomycin $\mathrm{C}$ (MMC) in distal and CCO where the obstruction was at least $7 \mathrm{~mm}$ from the punctum. ${ }^{9}$ Although the numbers in this study were small and without a control group, the high success rate suggests the use of MMC in combination with canalicular trephination warrants further study. Lacrimal intubation in the setting of CCO is considered useful in preventing closure of the canalicular lumen or membrane and is associated with a higher success rate. Transcanalicular techniques to address CCO have a low morbidity and limited invasiveness, therefore the need for a DCR may be questioned when the pathology is proximal to the lacrimal sac. However, direct visualization of 
the $\mathrm{CIO}$ allows one to distinguish mucosal folds more reliably from true membranes, ${ }^{23}$ and helps to avoid misdirection of the lacrimal probe or engagement of common canalicular or distal canalicular walls. Open lacrimal techniques allow more precise guidance of the trephine or lacrimal probe to emerge at the $\mathrm{CIO}$, reducing the risk of creating a false passage. We acknowledge the relatively small number of patients in this study; however, its prospective interventional design and strict inclusion criteria have allowed the identification of variable outcomes dependent on the location and nature of CCO. This study was not designed to compare different types of $\mathrm{CCO}$ or surgical technique, only to report outcomes. However, the findings suggest that thinner membranous $\mathrm{CCO}$ are associated with a higher anatomical and functional success rate than solid/thicker CCOs with whichever technique (membranotomy or trephination) is employed, although lacrimal intubation is important in all cases. The distinction between the membranous and thicker CCOs is subjective and made at the time of surgery. The deliberate differentiation of the site and extent of CCOs may assist with comparison of different treatments and their outcomes in future studies.

\section{Summary}

\section{What was known before}

- Retrospective studies of common canalicular obstructions (CCO) have shown that in the setting of external DCR surgery, membranectomy and silicone intubation, have an anatomic and functional success rate of $\sim 90 \%$ and $\sim 85 \%$, respectively. Published outcomes are difficult to compare between studies because of the variable definition of $\mathrm{CCO}$, with studies commonly grouping all CCOs together, without distinguishing between membranous and more solid distal CCO. Distal canalicular obstruction remains among the most common etiology cited for failure of primary DCR

\section{What this study adds}

- This is the first study to prospectively differentiate the outcome of CCO in the setting of endoscopic DCR (EnDCR) and lacrimal intubation based on the location and extent of the CCO.

- The anatomical and functional success rates for distal solid/thicker CCOs were $86 \%$ and $83 \%$, respectively, and $90 \%$ and $100 \%$ for thinner membranous obstructions. Membranotomy alone for $\mathrm{CCO}$ has not been previously investigated in the setting of EnDCR and was successfully utilized here without the need for trephination. Open lacrimal techniques allow more precise guidance of the trephine or lacrimal probe, reducing the risk of a false passage and distinguishing mucosal folds more reliably from true membranes.

\section{Conflict of interest}

The authors declare no conflict of interest.

\section{References}

1 Welham RA, Henderson PH. Results of dacryocystorhinostomy analysis of causes for failure. Trans Ophthalmol Soc UK 1973; 93(0): 601-609.

2 Boboridis KG, Bunce C, Rose GE. Outcome of external dacryocystorhinostomy combined with membranectomy of a distal canalicular obstruction. Am J Ophthalmol 2005; 139(6): 1051-1055.

3 Doucet TW, Hurwitz JJ. Canaliculodacryocystorhinostomy in the management of unsuccessful lacrimal surgery. Arch Ophthalmol 1982; 100(4): 619-621.

4 Hwang SW, Khwarg SI, Kim JH, Choung HK, Kim NJ. Bicanalicular double silicone intubation in external dacryocystorhinostomy and canaliculoplasty for distal canalicular obstruction. Acta Ophthalmol 2009; 87(4): 438-442.

5 Khoubian JF, Kikkawa DO, Gonnering RS. Trephination and silicone stent intubation for the treatment of canalicular obstruction: effect of the level of obstruction. Ophthal Plast Reconstr Surg 2006; 22(4): 248-252.

6 Sisler HA, Allarakhia L. New minitrephine makes lacrimal canalicular rehabilitation an office procedure. Ophthal Plast Reconstr Surg 1990; 6(3): 203-206.

7 Welham RA, Wulc AE. Management of unsuccessful lacrimal surgery. Br J Ophthalmol 1987; 71(2): 152-157.

8 Yang SW, Park HY, Kikkawa DO. Ballooning canaliculoplasty after lacrimal trephination in monocanalicular and common canalicular obstruction. Jpn J Ophthalmol 2008; 52(6): 444-449.

9 Nemet AY, Wilcsek G, Francis IC. Endoscopic dacryocystorhinostomy with adjunctive mitomycin $\mathrm{C}$ for canalicular obstruction. Orbit 2007; 26(2): 97-100.

10 Chan W, Fahlbusch D, Dhillon P, Selva D. Assisted local anesthesia for powered endoscopic dacryocystorhinostomy. Orbit 2014; 33(6): 416-420.

11 Andrew N, Selva D. Postoperative haemorrhage in powered endoscopic dacryocystorhinostomy. Clin Experiment Ophthalmol 2014; 42(3): 262-265.

12 Figueira E, Al Abbadi Z, Malhotra R, Wilcsek G, Selva D. Frequency of simultaneous nasal procedures in endoscopic dacryocystorhinostomy. Ophthal Plast Reconstr Surg 2014; 30(1): 40-43.

13 Shams PN, Selva D. Acute post-operative rhinosinusitis following endonasal dacryocystorhinostomy. Eye (London, England) 2013; 27(10): 1130-1136.

14 Cannon PS, Chan W, Selva D. Incidence of canalicular closure with endonasal dacryocystorhinostomy without intubation in primary nasolacrimal duct obstruction. Ophthalmology 2013; 120(8): 1688-1692.

15 Chan W, Selva D. Ostium shrinkage after endoscopic dacryocystorhinostomy. Ophthalmology 2013; 120(8): 1693-1696.

16 Munk PL, Lin DT, Morris DC. Epiphora: treatment by means of dacryocystoplasty with balloon dilation of the nasolacrimal drainage apparatus. Radiology 1990; 177(3): 687-690.

17 Wormald PJ. Powered endoscopic dacryocystorhinostomy. Laryngoscope 2002; 112(1): 69-72.

18 Sisler HA, Allarakhia L. A new ophthalmic microtrephine. Ophthalmic Surg 1990; 21(9): 656-657.

19 McLachlan DL, Shannon GM, Flanagan JC. Results of dacryocystorhinostomy: analysis of the reoperations. Ophthalmic Surg 1980; 11(7): 427-430.

20 McMurray CJ, McNab AA, Selva D. Late failure of dacryocystorhinostomy. Ophthal Plast Reconstr Surg 2011; 27(2): 99-101. 
21 Walland MJ, Rose GE. Factors affecting the success rate of open lacrimal surgery. Br J Ophthalmol 1994; 78(12): 888-891.

22 Beigi B, Uddin JM, McMullan TF, Linardos E. Inaccuracy of diagnosis in a cohort of patients on the waiting list for dacryocystorhinostomy when the diagnosis was made by only syringing the lacrimal system. Eur J Ophthalmol 2007; 17(4): 485-489.

23 Zoumalan CI, Joseph JM, Lelli GJ Jr., Segal KL, Adeleye A, Kazim $\mathrm{M}$ et al. Evaluation of the canalicular entrance into the lacrimal sac: an anatomical study. Ophthal Plast Reconstr Surg 2011; 27(4): 298-303.

24 Yazici B. Outcome of external dacryocystorhinostomy combined with membranectomy of a distal canalicular obstruction. Am J Ophthalmol 2006; 141(1):

229-230; author reply 230-221.

25 Paik JS, Cho WK, Yang SW. Bicanalicular double silicone stenting in endoscopic dacryocystorhinostomy with lacrimal trephination in distal or common canalicular obstruction. Eur Arch Otorhinolaryngol 2012; 269(6): 1605-1611. 